\title{
A review on crop losses, epidemiology and disease management of rice brown spot to identify research priorities and knowledge gaps
}

\author{
M. K. Barnwal • A. Kotasthane $\cdot$ N. Magculia • \\ P. K. Mukherjee • S. Savary • A. K. Sharma • \\ H. B. Singh • U. S. Singh • A. H. Sparks • \\ M. Variar $\cdot$ N. Zaidi
}

Accepted: 18 February 2013 / Published online: 10 March 2013

(C) The Author(s) 2013. This article is published with open access at Springerlink.com

\begin{abstract}
Rice brown spot (BS) is a chronic disease that affects millions of hectares of rice every growing season, grown by some of the most resource-poor farmers. Despite its widespread occurrence and impact, much still needs to be understood about BS. Reported yield losses in relative terms vary widely from 4 to $52 \%$. However, accurate, systematic estimates are lacking. BS is conventionally perceived as a secondary problem that reflects rice crops that experience physiological stresses, e.g. drought and poor soil fertility, rather than a true infectious
\end{abstract}

\footnotetext{
M. K. Barnwal

Department of Plant Pathology, Birsa Agricultural University, Kanke, Ranchi 834006 Jharkhand, India e-mail: barnwalbau@gmail.com
}

\section{A. Kotasthane \\ Department of Plant Molecular Biology and Biotechnology, College of Agriculture, IGKV, Raipur, India \\ e-mail: kotasthaneaj@yahoo.com}

N. Magculia $\cdot$ S. Savary $\cdot$ A. H. Sparks $(\bowtie)$ IRRI, Plant Breeding, Genetics and Biotechnology, Epidemiology and Crop Health Unit, DAPO, Box 7777, Los Baños, Philippines e-mail: a.sparks@irri.org

P. K. Mukherjee

NA \& BTD, B.A.R.C, Trombay, Mumbai 400085, India disease. Much remains to be understood about the mechanisms leading to epidemics and crop losses. Quantitative and qualitative knowledge gaps exist in our understanding of the epidemiological processes, sources of resistance and biocontrol methods. In this review we identify several of these gaps, which if filled, could lead to a strong impact on the management of brown spot. We also use the architecture of a simulation model to position and prioritize these knowledge gaps, assess the epidemiological consequences of disease management options on

\footnotetext{
A. K. Sharma

G.B. Pant University of Agriculture \& Technology,

Pantnagar, India

e-mail: anilksharma_99@yahoo.com

H. B. Singh

Department of Mycology and Plant Pathology,

Institute of Agricultural Sciences, Banaras Hindu University,

Varanasi 221005, India

e-mail: hbs1@rediffmail.com

U. S. Singh $\cdot$ N. Zaidi

IRRI Office, Delhi, NASC, Pusa, New Delhi 110012, India

U. S. Singh

e-mail: u.singh@irri.org

N. Zaidi

e-mail: n.zaidi@irri.org
} 
BS monocyclic processes and explore the impact changing production situations on this important disease.

Keywords Bipolaris oryzae $\cdot$ Oryza sativa $\cdot$ Systems analysis

\section{Abbreviations \\ BS Rice brown spot \\ QTL Quantitative trait locus}

\section{Introduction}

Rice brown spot (BS), caused by Cochliobolus miyabeanus (Ito and Kuribayashi) Drechs. ex Dastur. (Anamorph: Bipolaris oryzae (Breda de Haan) Shoemaker), is an orphan disease of rice, despite the fact that the disease chronically affects millions of hectares worldwide every year (Chakrabarti 2001; Padmanabhan 1973; Savary et al. 2000a; Zanão Júnior et al. 2009). It especially occurs in environments where water supply is scarce and it is often combined with imbalances in plant mineral nutrition, especially the lack of nitrogen. These factors are commonly associated with resourcepoor farmers' fields (Ou 1985; Zadoks 1974), which at this beginning of the 21 st century, are still

\section{Variar}

Central Rainfed Upland Rice Research Station, P.O. Box 48, Hazaribag 825301 Jharkhand, India e-mail: mukund.variar@gmail.com

Present Address:

N. Magculia

Laboratory of Plant Pathology, Graduate School of Agricultural Science, Kobe University, 1-1 Rokkodai, Nada, Kobe 657-8501, Japan

e-mail:n.magculia@gmail.com

Present Address:

P. K. Mukherjee

Central Institute for Cotton Research, Shankarnagar,

Nagpur, India

e-mail: prasunmala@gmail.com

Present Address:

S. Savary

INRA Centre de Recherche de Toulouse, UMR 1248 AGIR, Auzeville, BP 52627, 31326 Castanet-Tolosan Cedex, France

e-mail: Serge.Savary@toulouse.inra.fr tilled by the majority of the most resource-poor farmers in the world. These disease-conducive factors also correspond to the often overlooked notion of disease predisposition (Schoeneweiss 1975). These factors are well documented in other rice diseases of favourable environments, such as sheath blight, bacterial blight, or leaf blast (Ou 1985; Reddy et al. 1979; Savary et al. 1997). BS might be strongly associated with the combined plant physiological disorders, disease development processes, and disease resistance mechanisms. This association between exposure to physiological stresses and disease development brings about generic and important questions pertaining to interacting metabolic pathways, their genetic bases and the interaction amongst genes or clusters of genes (e.g. Igawa et al. 2005; Timmusk and Wagner 1999).

BS has been the subject of several earlier reviews (e.g. Padmanabhan 1973; Gangopadhyay and Chakrabarti 1987; Chakrabarti et al. 1992; Chakrabarti 2001), which provide overviews on the disease. This review is intended to specify knowledge gaps that could lead to much-needed, high-impact research. To pinpoint these knowledge gaps we address a series of linked questions by constructing and using a simple simulation model.

Importance of brown spot

Brown spot has been associated with two major epidemics in India, the first in 1918-19, in the KrishnaGodavari delta and the second, during 1942 in today's India and Bangladesh (Chakrabarti 2001). The latter of which has been associated with the Great Bengal Famine (Chakrabarti 2001; Padmanabhan 1973). One has, however, to remember that the relationship between plant disease epidemics and famines seldom and probably never is simple, as so many other factors lead to major social consequences (Chakrabarti 2001; Zadoks 2008).

Brown spot is still widely reported across India (Reddy et al. 2010) and more generally in the South and South-East Asian countries (Savary et al. 2000a). It causes yield losses that, on average, are in the range of $10 \%$ of the attainable yield wherever it occurs (Savary et al. 2000b, 2006) in the lowlands of tropical and subtropical Asia. Therefore, BS is by far one the strongest yield reducers amongst rice diseases today. Further, there 
is indication that $\mathrm{BS}$ is becoming more frequent and severe as drought is becoming more frequent (Savary et al. 2005), perhaps due to increased variability in rainfall.

The range of reported yield losses to BS, often expressed in relative terms, is variable from 4 to $29 \%$ (Bedi and Gill 1960), about $12 \%$, (Aluko 1975), from 8 to $23 \%$ (Fomba and Singh 1990) from 26 to $52 \%$ (Chakrabarti 2001). The latter figures represent a broader and higher range because it accounts for losses caused by grain infection. Heavily infected grains are not suitable for human consumption, which may partly explain the impact of BS in the Great Bengal Famine.

Brown spot exemplifies a group of pathosystems with similar epidemiological, biological and environmental attributes having equivalent consequences. One of them is the leaf blotch disease of wheat (Duveiller and Sharma 2009), another chronic disease that especially affects the poor in the same regions of the world, especially in South Asia. Other examples include angular leaf spot of bean of Central and South America (Allorent and Savary 2005; Bergamin Filho et al. 1997) or alfalfa leaf spot (Thal and Campbell 1988), with their strong leaf senescence effects and similar implications on plant growth, disease dynamic, and plant-water balance. One may thus consider BS as a model pathosystem for a synergistic understanding on a range of diseases (Savary et al. 2011).

\section{Review of knowledge on epidemiology, crop losses and management}

Little is known about on the frequency at which BS occurs; the areas that are affected; the intensity of the disease; the magnitude of future changes in frequency, distribution and intensity; and the yield losses the disease may actually cause given the large variation in reported results.

A number of damage mechanisms (Rabbinge and Rijsdijk 1981; Rabbinge and Vereyken 1980; Savary et al. 2006) lead to BS yield losses, in addition to leaf area index (LAI) reduction and presumably selfshading of lesions on underlying canopy. These also include an early senescence of the diseased plants (Klomp 1977) a reduction of the number of tillers and a reduction of root and shoot elongation (Vidhyasekharan et al. 1973).
Life cycle of brown spot

\section{Primary inoculum}

The available information regarding the nature and importance of different sources of inoculum is patchy and mostly non-quantitative. According to Sharma and Maheshwari (1982) and Damicone et al. (2001) primary infections are seed-borne (Damicone et al. 2001; Ellis and Holliday 1971; Nyvall et al. 1995; $\mathrm{Ba}$ and Sangchote 2006; Spradley et al. 2003) while secondary infections arise from wind-borne inoculum generated by infested debris such as rice straw and stubble (Ou 1985; Sato et al. 2008). Soil and some weed hosts also have been reported as inoculum reservoirs (Biswas et al. 2008).

\section{Infection efficiency}

A number of inoculation methods for BS have been tested (Akai et al. 1965; Ba and Sangchote 2006). Bipolaris oryzae conidia are multicellular, usually germinate bipolarly at maturity and may generate more than one infection point (Ou 1985). Optimal temperatures for conidial germination $(25-30 \mathrm{C})$ (Nisikado 1923) and hyphal growth (27-30 C) (Nisikado 1923) correspond to optimum temperatures for infection and lesion expansion (Dasgupta and Chattopadhyay 1977; Imura 1940; Sherf et al. 1947). Increasing leaf wetness periods in rice canopies (Luo 1996) generally led to increased lesion densities (Imura 1940; Percich et al. 1997; Sherf et al. 1947). Padmanabhan and Ganguly (1954) demonstrated that the susceptibility of plant tissues increase with their age.

\section{Incubation, latency and infectious periods}

As in many necrotrophic foliar pathogens, the incubation period is short (within 24 h) (Klomp 1977; Sarkar and Sen Gupta 1977). The infectious period initiates rapidly (three to four days) (Ba and Sangchote 2006) and sporulation peaks about 6 days after infection (Sarkar and Sen Gupta 1977). Results from Sarkar and Sen Gupta (1977) suggest that delays in the BS life cycle are similar to those of Helminthosporium turcicum of maize, approximately 6 and 19 days for the latency $(p)$ and the infectious $(i)$ periods (Levy and Cohen 1980). 
Factors affecting the life cycle and brown spot epidemics

\section{Rainfall and drought}

Brown spot is generally not observed in years with regular rainfall (Singh et al. 2005) whereas seasons with limited rainfall but heavy dew are conducive to stronger epidemics (Sherf et al. 1947). Within a 5-year period (2000-2004) two rainy season crops (2001 and 2003) in India led to terminal severities of 9.2 to $8.8 \%$, corresponding to accumulated rainfalls of 410.5 to $502.0 \mathrm{~mm}$, respectively. However, in 2002 lower rainfall corresponded with higher severity (Pannu et al. 2005).

Drought has long been recognized as a key factor favouring BS epidemics. Early studies indicated that water shortage enhances BS (Hemmi and Suzuki 1931; Su 1938) leading to more disease occurring in rain-fed versus irrigated/flooded crop stands (Hegde et al. 1999; Kulkarni et al. 1979).

\section{Temperature and humidity}

Overall, temperature does not appear to influence BS epidemics (Dasgupta and Chattopadhyay 1977). However, temperature and humidity, in the form of leaf wetness, interact on infection efficiency (Percich et al. 1997). This may explain why decreasing daily minimum temperatures $(9.3$ to $7.5 \mathrm{C}$ ) lead to more severe epidemics (Minnatullah and Sattar 2002).

\section{Plant nutrition and their interactions on disease development}

The literature dealing with soil characteristics, plant nutrition, plant physiology and BS is large and diverse. The interactions between plant mineral nutrition with a range of other factors influencing the disease have also been addressed. Only some main features are outlined here.

Brown spot has long been associated with soil fertility (Damicone et al. 2001; Ou 1985), for which the disease sometimes is considered a marker. Ou (1985) concluded his review on BS in considering that the main factor governing BS is the "physiological condition of the rice plant", a strong reflection of soil characteristics. The literature has conventionally emphasized mineral deficiencies, e.g. of N (Misawa 1955; Phelps and Shand
1995), of K (Padmanabhan et al. 1962), P (Singh et al. 2005), P and K (Chattopadhyay and Chakrabarti 1965), N or K (Carvalho et al. 2010; Spradley et al. 2003), or $\mathrm{Si}, \mathrm{Mn}$ and K (Wang et al. 1980). Deficiencies of these elements interact (Chakrabarti 2001; Ou 1985), which may partly explain the occurrence of optimum response patterns as in the case of $\mathrm{N}$ (e.g. Chattopadhyay and Dickson 1960). Phelps and Shand (1995) documented the interaction between $\mathrm{N}$ and $\mathrm{P}$ on BS susceptibility and showed an optimum pattern as a function of $\mathrm{P}$ supply if the $\mathrm{N}$ supply is near optimal. Further, differences in rates of leaching from the soil amongst these elements (Chakrabarti 2001) bring about a link between soil nutrient effects with both soil texture and rainfall patterns. One additional factor is that of the effects of nutrients depend on the redox potential of the soil, which has been described in numerous reports (Ou 1985).

One element, silicon, stands apart from the others. Si exerts beneficial effects on plant growth and production by alleviating both biological injuries and physiological stresses. Si-based amendments appear to address one of the main causes for susceptibility and could be one avenue for the management of BS in areas where soils are low or limiting in plant-available Si (Datnoff et al. 1991, 1997).

Recent advances in the understanding of the molecular mechanisms, specifically transporters involved in Si uptake by roots (Dallagnol et al. 2010; Ma et al. 2006, 2007) and distribution within the plants (Yamaji et al. 2008) may lead to breeding for multiple disease resistance and tolerance to physiological stresses through improvement of the roots' Si uptake capacity and Si distribution within plants.

A shortage of water may result in reduced availability of certain micronutrients (Weil and Holah 1989) because mineral nutrition depends on water uptake (Allaway 1968; Gardner et al. 1985). Water supply also influences the pattern of BS response in rice to nutrients, as in the case of $\mathrm{P}$, which follows an optimum curve when water is scarce (Singh et al. 2005).

Therefore complex interactions between water supply, nutrients, soil characteristics and BS are at play. Most of the available reports do not address processes themselves, nor do they provide quantitative factorand-effect relationships. Three factors appear to be critical for a better understanding of BS epidemics and their management: the role of nutrients in disease 
predisposition, the effect of drought (in interaction with the former component) and the interplay of the first two factors with soil characteristics on the hydromineral plant nutrition.

\section{Host plant resistance (HPR)}

Host plant resistance to disease is an effective and economical way to manage BS. However, breeding efforts have emphasized acute diseases such as leaf blast and bacterial blight rather than chronic diseases such as BS (Savary et al. 2011) despite the importance of BS.

\section{Sources of resistance}

The search for sources of resistance to BS has been a long-standing effort (Chakrabarti 2001; Nagai and Hara 1930). Satija et al. (2005) identified 15 Oryza sativa entries out of 124 that were classified as resistant (less than $5 \%$ severity). Conversely, Hossain et al. (2004) identified one resistant variety out of 29 entries. Screening of upland rice germplasm, exotic and indigenous to Eastern India, has revealed that partial and complete resistance to the BS pathogen is expressed by several genotypes under field conditions (Shukla et al. 1995). It seems that the sources of resistance amongst Oryza sativa entries are few and recent research (e.g. Goel et al. 2006) has been exploring other pools, especially $O$. nivara.

\section{Major genes}

Adair (1941) suggested that resistance was recessive, involving several genes. Later studies showed that resistance, or susceptibility, could be associated with a limited number of genes. Balal et al. (1979) found two dominant genes were associated with resistance, while one gene was associated with susceptibility.

\section{Partial resistance}

Goel et al. (2006) analysed the inheritance of resistance to BS from crosses involving $O$. nivara germplasm and hypothesized that additive, dominant and gene interactions were involved. Three quantitative trait loci (QTL) were detected in cultivar Tadukan (qBS2, qBS9, qBS11) on chromosomes 2, 9 and 11, respectively (Sato et al. 2008) qBS11 being considered as having a major effect. However, Katara et al. (2010) identified 10 QTLs, some of which may be common to the results by Sato et al. (2008).

\section{Biological control of brown spot}

There have been only a few reports on the improvement of BS control involving biological control agents. However, the use of antagonistic microbes for plant health management has emerged as a viable technology in the recent past. Commercially available antagonistic microbes, mostly belonging to the genera Pseudomonas and Trichoderma, can reduce the damage by direct effects on the pathogens (mycoparasitism, antibiosis, competition for iron) or by improving plant immunity (induced resistance, IR) (Singh et al. 2005). Direct antagonism has been the key factor in suppression of many soil-borne pathogens, while IR is active against diverse foliar pathogens including both bacteria and fungi (Shoresh et al. 2010).

Seed treatments with Trichoderma viride or $T$. harzianum have reduced disease by $70 \%$ (Biswas et al. 2010). Over $70 \%$ disease reduction has been achieved too from the use of selected Pseudomonas spp. isolates (Joshi et al. 2007; Ludwig et al. 2009). Direct foliar application of T. harzianum has also been reported to reduce the disease intensity and significantly improve grain yield, total grain carbohydrate and protein, in addition to a significant improvement in the total photosynthetic pigments in rice leaves (Abdel-Fattah et al. 2007).

Such an alternative mode of BS management is largely untapped, but holds great promise. Trichoderma spp., well-known mycoparasites, can colonize roots internally and help improving nutrient uptake and mobilization, enhance nitrogen use efficiency, promote root growth and plant biomass, and improve tolerance to various physiological stresses, including soil salinity and drought through the reduction of oxidative damage that stresses cause (Harman 2011; Shoresh et al. 2010). Use of these microbes could suppress disease through direct antagonism against the pathogen because imbalanced plant nutrition and drought stresses are predisposing factors for BS development. This effect would be combined with improved plant nutrient supply and delayed onset of water deficit in plant tissues (Bae et al. 2009) altering plant physiology to the disadvantage of the pathogen. Further, these microorganisms could contribute to the build-up of active plant immunity through the activation 
of the defence pathways, similar to the effects of $P$. fluorescens on rice, which induce resistance to sheath blight (Nandakumar et al. 2001).

\section{Identification of knowledge gaps we wish to address}

(i). why are BS epidemics so slow to initiate and increase;

(ii). why is BS such a persistent disease in some riceproducing areas and less so in others;

(iii). what are the sources of primary inoculum and their quantitative role in the course of epidemics;

(iv). how can host plant resistance be best characterized screened and deployed;

(v). what are the physical factors (and the physiology of the host plant) that must be accounted for in so doing;

(vi). what genes (including Quantitative trait loci, QTL) are involved in both susceptibility (resistance) to BS and tolerance to physiological stress, (e.g. drought) and how could they interact; and

(vii). what interactions of micro-organisms with the host plant and/or the pathogen trigger could cascade reactions that hamper, or favour, resistance to disease and tolerance to physiological stresses?

The first hypothesis that we put forward is that the genetic bases of rice tolerance to unfavourable physical environment and of rice resistance to the pathogen are connected. If so, addressing one group could produce advances on the other.

A second hypothesis is that scientific advances on BS as a model pathosystem to which many other plant diseases (leaf diseases caused by necrotrophs under harsh environmental conditions and inducing leaf senescence, such as wheat leaf blotch) could enable a synthesis in approaches to understand and manage this group of diseases. This has particular relevance in the context of climate change and global change-induced shortage of resources for agriculture.

Illustration of knowledge gaps using a simple conceptual simulation model

Simulation modelling is a powerful approach to: (i) identify knowledge gaps; (ii) quantify reactions of epidemiological processes in response to varying parameters and driving functions; and (iii) explore the outcomes of changes in the contexts under which epidemics take place (e.g. Segarra et al. 2001; Allorent and Savary 2005).

Knowledge gaps are materialised by parameters, with specific meanings and dimensions (Rabbinge 1982), which have strong influences on the model's behaviour. Epidemiological reactions to variable conditions include, but are not limited to, the physical environment; they may also include levels of partial resistance (Zadoks 1971). Changes in contexts where disease may develop involve the levels of primary inoculum or disease control (Van der Plank 1963; Zadoks 1971; Segarra et al. 2001) as well as yet-tocome, or possible shifts, in agricultural contexts where epidemics occur.

A simplified simulation model using a time-step of 1 day and a system size of $1 \mathrm{~m}^{2}$ was developed (Fig. 1) including a series of state variables, which represents sites where infection may take place. The considered system is supposed to be surrounded by equivalent systems (a number of other $1-\mathrm{m}^{2}$ crop stands, i.e. a rice field) in a steady state. The state variables are: the numbers of healthy sites (sites), of latent sites (lat), of infectious, not senesced, sites (infC), the number of infectious, senesced (infD) sites, the amount of sites that are removed from the epidemiological process (rem). This structure is similar to that of the model used by Allorent and Savary (2005) and Savary et al. (2012).

The model incorporates a rate of primary infection (RINF), a rate of crop (site) growth (RG), a rate of senescence of healthy tissues (Ref) and a rate of removal (remov) of tissues from the infectious process (Fig. 1). RINF in turn depends on the fraction of sites that are available (i.e. non infected) at a given time (COFR), on the intrinsic rate of infection per day, $\mathrm{R}_{\mathrm{c}}$ (Van der Plank 1963; Zadoks 1971) and on the presence of primary inoculum (INOCPRIM), which determines the onset (Start) of the epidemic. Following Klomp (1977) we set $R_{c}$ at $0.61 t^{-1}$. Note that $R_{c}$ is directly linked to the net reproductive number, $\mathrm{R}_{0}$, since:

$\mathrm{R}_{0}=\int \mathrm{R}_{\mathrm{c}}$ over the time interval: $\mathrm{t}$ and $\mathrm{t}+\mathrm{i}$, where $\mathrm{i}$ is the infectious period (Segarra et al. 2001).

RINF further depends on two feedback loops (Allorent and Savary 2005) representing infections from infectious, not senesced, sites (infC) and from infectious, senesced (infD) sites, respectively. 


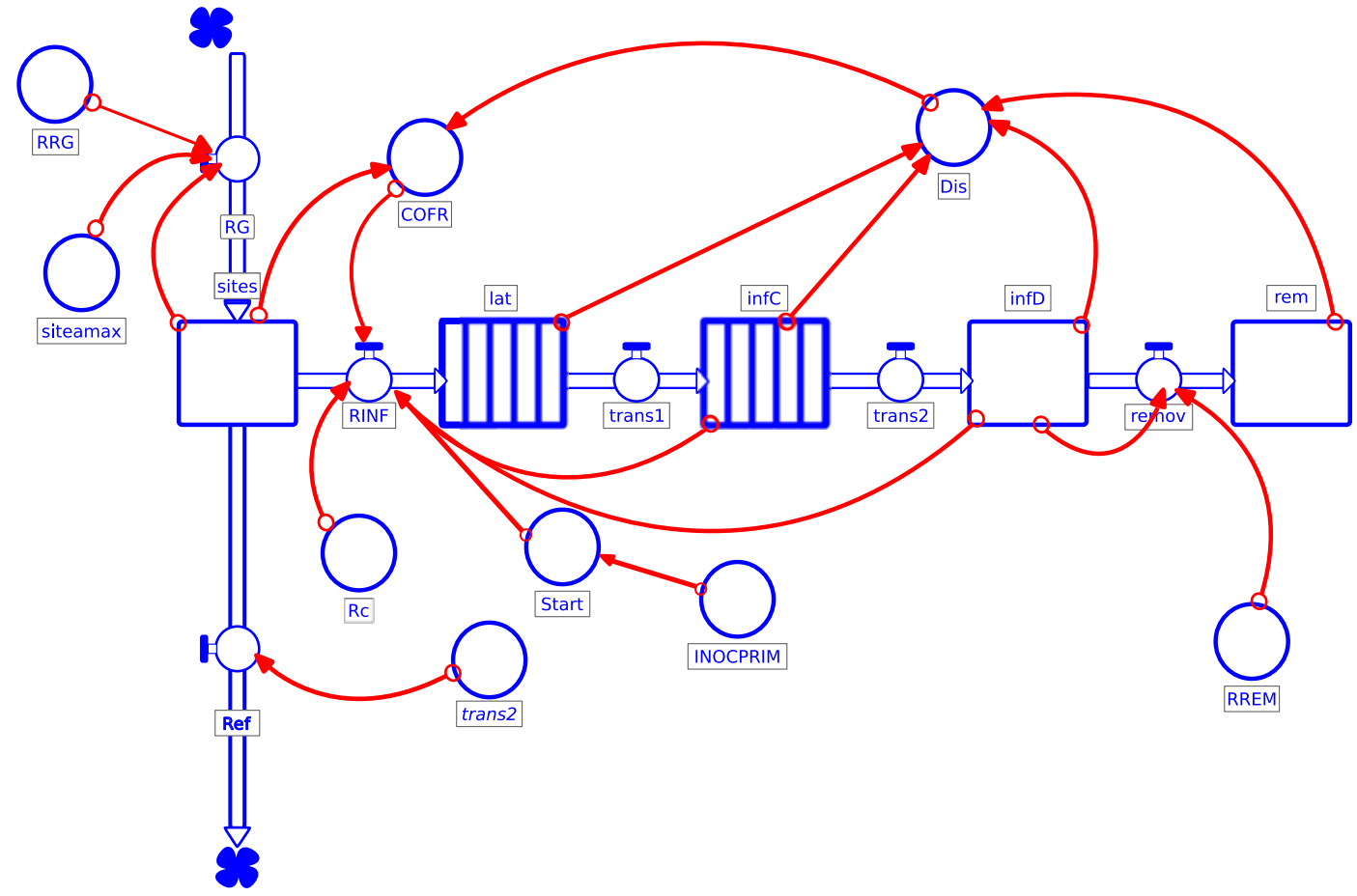

Fig. 1 Flowchart diagram of a simplified model for brown spot epidemics, where: sites, the number of healthy sites; lat, number of latent sites; infC, number of infectious, not senesced sites; infD, number of infectious, senesced sites; rem, the amount of sites that are removed from the epidemiological process; RINF, primary rate of infection; RG, rate of crop (site) growth; Ref,

The model was parameterized using data from the literature. The latency period, $p$, was derived from Sarkar and Sen Gupta (1977) and Levy and Cohen (1980) and set at 6 days. The value of $i$, the infectious period, was also derived from Sarkar and Sen Gupta (1977) and Levy and Cohen (1980) and set at 19 days. The duration of the infectious period in the senesced tissue is unknown to our knowledge, but given the structure of the model, depends on the rate of removal. This latter rate depends on a relative rate of removal, which we set to $0.01 \mathrm{~d}^{-1}$ (i.e. $1 \%$ of the senesced, infectious sites are removed daily) following Yoshida (1981) and Willocquet et al. (2000, 2004). The rate of growth was determined on the site size (i.e. average potential lesion size) in a rice canopy, which we derived from (Dasgupta and Chattopadhyay 1977). The model initiates epidemics when crop stands have 10000 such sites, until they have a maximum site size of 100000 (i.e. sitemax $=100000$ ). In order to achieve such a site size in a 120-day period of time (a common rate of senescence of healthy tissues; remov, rate of removal of infectious tissues from the infectious process; COFR, the fraction of non-infected sites at time $i$; Rc intrinsic rate of infection per day; trans2, the rate of senescence of infected tissues; INOCPRIM, presence of primary inoculum which determines the onset (Start) of the epidemic

crop cycle duration in rice) a relative rate of growth (RG) of 0.1 (i.e. 0.1 new sites produced per healthy site per day) was found appropriate, which concurs with earlier publications (Willocquet et al. 2000, 2004; Yoshida 1981).

\section{Some key hypothesis of the model}

A number of hypotheses are associated with this model structure (Van der Plank 1963; Zadoks 1971; Segarra et al. 2001; Allorent and Savary 2005), which pertain to the representativeness of the considered system, the equilibrium in propagule flows between the considered systems and its neighbours and the even distribution of lesions in the canopy. Numerous reports have shown that such a model structure provides a reasonable basis to generate insights on the behaviour of many epidemiological systems. A few additional hypotheses used here (Fig. 1) should be emphasised: 
(1) The rates of senescence of diseased and healthy tissues are assumed equal in the model. This implies that, similarly to the lesion distribution, the spatial distribution of senescence is even in the canopy and is driven by disease. This hypothesis is derived from the studies by Klomp (1977) but should be better documented with respect to other senescencerelated factors.

(2) The non-senesced tissues were arbitrarily made four times more infectious than senesced tissues. We are not aware of reports quantifying the infectiousness of infected tissues, senesced or not. As a hypothesis, the model considers that an infectious site belonging to a senesced leaf is less likely to infect healthy sites because of the shrivelling and bending of senesced leaves. Infectious sites on senesced leaves are less likely to infect healthy ones that are located primarily in the upper part of the canopy. By contrast, healthy sites surround infectious sites on non-senesced tissues. This hypothesis is consistent with Allorent and Savary (2005) and Allorent et al. (2005). Thus we wrote: $\mathrm{R}_{\mathrm{c}}{ }^{*} \mathrm{COFR} *\left(\mathrm{infD}^{*} 0.8+\right.$ infC*0.2) + Start.

(3) We chose to start epidemics with 1,10 and 30 effective propagules infecting on day 20 after crop establishment. We are not aware of reports on the time of onset of BS epidemics. The importance of epidemic onset date and strength can easily be analysed using this model, but their quantification would require specific experimental work. Nevertheless, preliminary runs indicated that there were no observable differences noted among the number of effective propagules at the start of the epidemic and all three choices yielded disease progress curves that concur with the shape of typical BS epidemics (Klomp, 1977; Pannu et al. 2005).

\section{Observations from the model}

Figure 2 shows that when the model is run with standard, literature-derived parameters (thin, continuous curve) the simulated BS epidemics behave as reported in the literature (Klomp, 1977; Pannu et al. 2005). The intrinsic rate of disease increase, $R_{c}$, has a strong effect on the rate of disease increase and on the level of terminal severity: a $50 \%$ increase in $\mathrm{R}_{\mathrm{c}}$ results in a three-fold increase in terminal severity. This occurs despite the senescence, and the progressive removal of plant tissues, i.e. despite the faster disappearance of infectious tissues. Conversely, a reduction in $\mathrm{R}_{\mathrm{c}}$ by $50 \%$ strongly reduces (by about $90 \%$ ) the level of terminal severity. This suggests that any factor that reduces $R_{c}$ will have strong effects on disease increase. Since $\mathrm{R}_{\mathrm{c}}=\mathrm{N} * \mathrm{E}=$ [Number of effective (deposited) propagules] * [Infection efficiency] (Zadoks 1971), these factors include: a partial resistance to infection (i.e. a reduction of $\mathrm{E}$ ); a partial resistance to propagules formation; microclimatic conditions enabling: (i) spore formation, (ii) spore liberation and deposition, and (iii) infection; and host physiological predisposition (water stress, nutrient uptake) and response with respect to infection.

The simulated BS epidemics strongly respond to $p$, the duration of the latency period: a $50 \%$ decrease in $p$ results in a more than three-fold increase in terminal severity; a $50 \%$ increase in $p$ results in an approximately $60 \%$ reduction in terminal severity (Fig. 3). This suggests that any factor that increases $p$ will have strong effects on disease increase. These factors include: a partial resistance in the latency period; and host physiological predisposition (water stress, nutrient uptake) and response during the host colonisation process.

The simulated BS epidemics are essentially insensitive to variations in RREM (Fig. 4) the relative rate of removal of infected, senesced, tissues. This suggests that this process is not a critical phase of the epidemiological process, nor is it an entry point for disease management.

The simulated BS epidemics respond to INOCPRIM, the amount of primary inoculum, but to a lesser extent than they do to variations in $\mathrm{R}_{\mathrm{c}}$ and $p$. This suggests that any factors that decreases INOCPRIM will have some effects on disease increase, but only if INOCPRIM is greatly reduced. These factors include: biological control agents, which are discussed in later a later section of this paper, and the existence and amount of primary inoculum in crop residues or secondary hosts. This therefore suggests that biocontrol, in order to be effective, must result into a large reduction of the primary inoculum.

Our model suggests that to achieve suitable control there needs to be a substantial reduction in initial (e.g., seed-borne) inoculum to measurably suppress BS (Fig. 5). 
Fig. 2 Sensitivity of analysis of changes to Rc $( \pm 50 \%)$ in BS pathosystem. Initial parameter values were: INIT sites, $10000 ; \mathrm{Rc}=0.61$; $\mathrm{RRG}=0.1 ; \mathrm{LP}=6$ days; sitemax $=100000 ; \mathrm{IP}=$ 19 days; INOCPRIM $=10$, $\mathrm{RINF}=\mathrm{Rc} * \mathrm{COFR}(\mathrm{infD} * 0.8$ $=\operatorname{infC} * 0.2)+$ Start; RREM $=0.01$
Sensitivity analysis: Rc

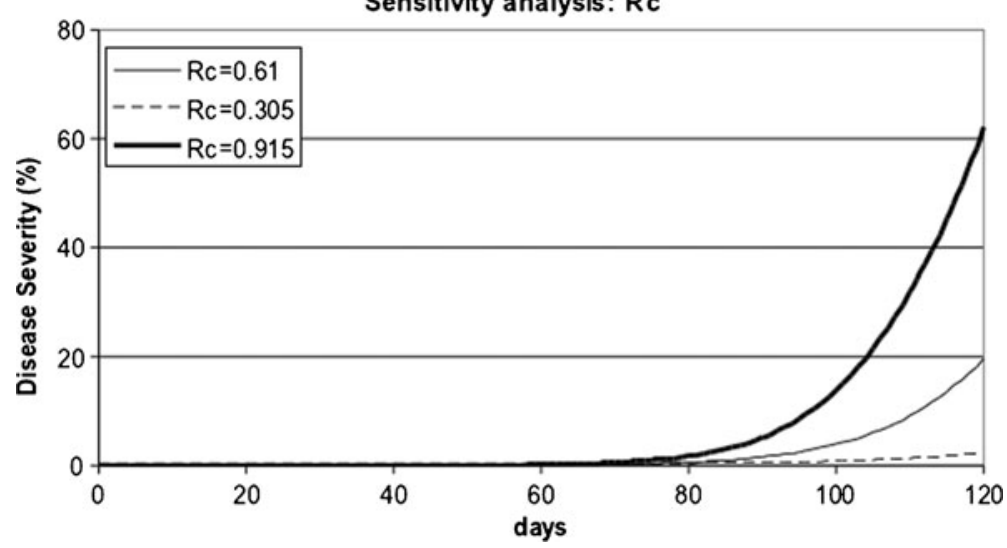

\section{Identification of research priorities to address knowledge gaps}

Life cycle of brown spot

\section{Primary inoculum}

Assessing the respective strength of inoculum from the afore-mentioned multiple sources is difficult. It appears likely that transmission through infected seeds is perhaps a dominant process in many BS epidemics. This indicates that a strong reduction of seed infection in the field, possibly combined with seed treatments (Biswas et al. 2008), might translate into good disease management. Ludwig et al. (2009) reported reductions in disease severity using both synthetic fungicides and biocontrols as a seed treatment when inoculating leaves and panicles. Our model suggests that to achieve suitable control there needs to be a substantial reduction in initial (e.g., seed-borne) inoculum to measurably suppress BS (Fig. 5). This entry point for disease management should be addressed as one component of an overall research effort Fig. 6.

\section{Infection efficiency}

Strangely, the above references do not provide specific measures of infection efficiency $(E)$. Little is known of the variation in $E$, or of the predisposing factors to infection. A good understanding of these factors is key to addressing issues such as the field conditions under which disease may establish, the speed at which epidemics may unfold and the assessment of host plant resistance. A replicable, reliable inoculation technique incorporating quantified measurements of predisposing factors would be a major outcome of research with many applications.

\section{Incubation, latency and infectious periods}

We know little about delays $(i, p)$ involved in the disease cycle and the factors influencing them. Many
Fig. 3 Sensitivity analysis of changes in latency period p: $\pm 50 \%$
Sensitivity analysis: $p$

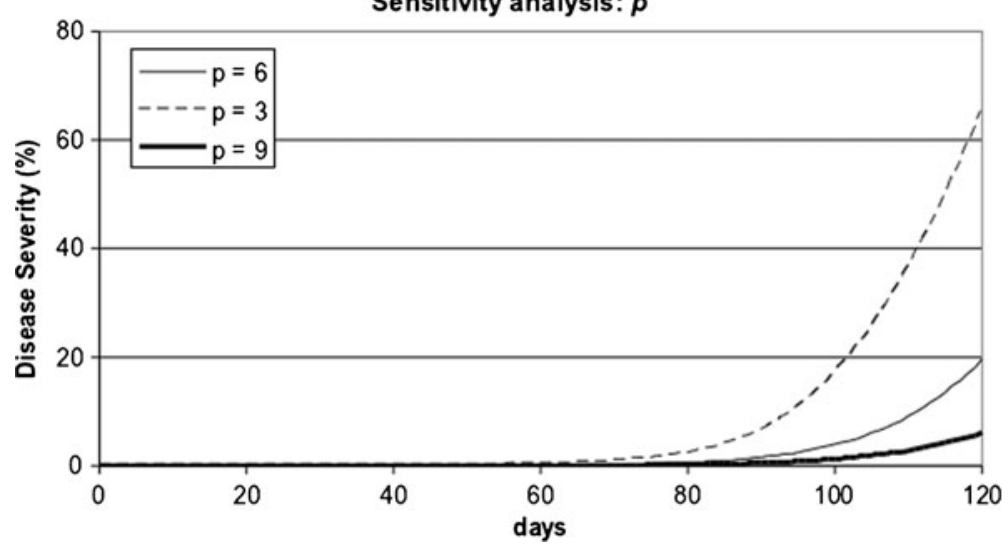


Fig. 4 Sensitivity analysis of RREM: $\pm 50 \%$

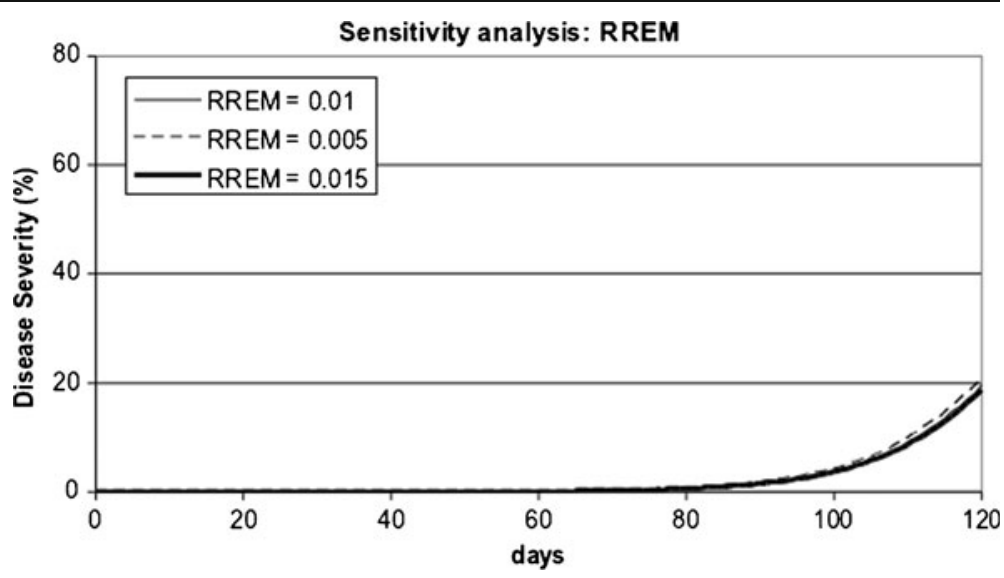

authors refer to the incubation period, rather than to the epidemiologically critical residence times, $i$ and $p$ (Van der Plank 1963).

Few quantitative data regarding $p$ in $\mathrm{BS}$ are available, which do not always concur. Measuring $p$, its variability the effect of environmental factors and effects of several popular rice varieties, may document a possibly important component of partial resistance. Thus this should be part of an overall research agenda on BS. Measuring $i$ is timeconsuming and often difficult. Yet, its quantification would enable a complete quantitative coverage of the monocycle in BS.

Sensitivity analyses of changes to the intrinsic rate of infection per day $(R c)$ and thus, of $E$ (Van der Plank 1963; Zadoks 1971) and changes to the infection period (p) indicate that a reduction in $R c$ or $p$ by $50 \%$ has a significant effect on disease severity (Figs. 2 and 3 ). This suggests that methods that reduce $E$ or increase $p$ could strongly contribute in controlling BS. By contrast, removal of infected tissue seems to have little effect
(Fig. 4) and would not seem to be an entry point for control efforts.

Factors affecting the life cycle and brown spot epidemics

\section{Plant nutrition and their interactions on disease development}

Recent advances in the understanding of the molecular mechanisms, specifically transporters involved in $\mathrm{Si}$ uptake by roots (Dallagnol et al. 2010; Ma et al. 2006, 2007) and distribution within the plants (Yamaji et al. 2008), may lead to breeding for multiple disease resistance and tolerance to physiological stresses through improvement of the roots' Si uptake capacity and Si distribution within plants.

Complex interactions between water supply, nutrients, soil characteristics and BS are at play. Most of the available reports do not address processes themselves, nor do they provide quantitative factor-and-
Fig. 5 Sensitivity analysis of initial inoculum: INOCPRIM $+50 \%,+100 \%$ or $-50 \%,-90 \%$

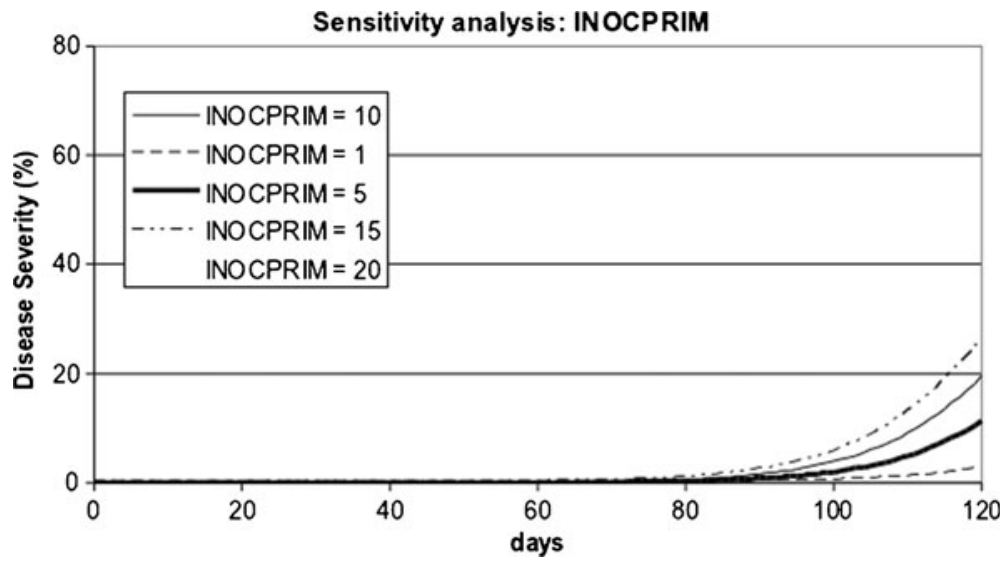


Fig. 6 Flowchart diagram illustrating: the main conclusions of the review driving the main steps and recommendations for future research

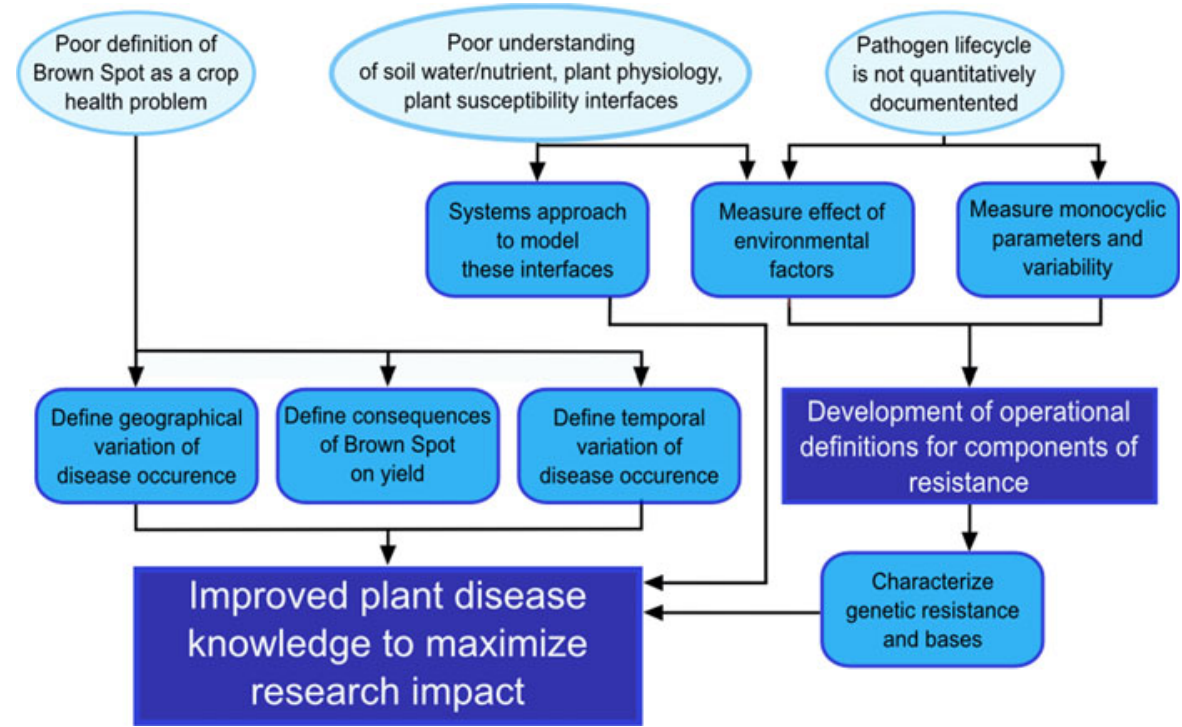

effect relationships. Three factors appear to be critical for a better understanding of BS epidemics and their management: the role of nutrients in disease predisposition, the effect of drought (in interaction with the former element) and the interplay of the first two factors with soil characteristics on the hydro-mineral plant nutrition.

Host plant resistance (HPR)

Host plant resistance to disease is an effective and economical way to manage BS. However, breeding efforts in rice have emphasized acute diseases such as leaf blast and bacterial blight rather than chronic diseases such as BS (Savary et al. 2011) despite its importance.

\section{Quantification of processes and understanding mechanisms underlying resistance}

The above elements suggest that work is still required on the topic. There is a need to first identify the respective roles of different genes involved in the resistance of rice to BS. Some genes might be major as suggested by earlier work and might interact with a number of genes with quantitative effects. A second area, which is methodologically connected to the first, is to develop approaches to quantify resistance given the specific conditions under which BS develops, a unified and standardized procedure for testing material is required. A third is to develop a methodology enabling to pinpoint which phase of the disease cycle should be targeted to achieve the largest epidemiological impact. Components of resistance to BS still remain to be defined and linked to results generated by breeders. Further, it appears that no specific quantitative attention has been given to the interaction between partial resistance and environmental factors. For instance, it could well be that some QTLs are better expressed under some specific environments than others. There is also need to explore the linkages, among identified QTLs for drought tolerance and BS resistance.

\section{Biological control of brown spot}

There have been only a few reports on the improvement of BS control involving biological control agents. The use of antagonistic microbes for plant health management has emerged as a viable technology in the recent past. Such an alternative mode of BS management is largely untapped, but holds great promise.

Commercially available antagonistic microbes, mostly belonging to the genera Pseudomonas and Trichoderma, can suppress diseases by direct effects on the pathogens (mycoparasitism, antibiosis, competition for iron) or by improving plant immunity (induced resistance, IR) (Singh et al. 2005). Direct antagonism has been the key factor in suppression of many soil-borne pathogens, while IR is active against diverse foliar pathogens including both bacteria and fungi (Shoresh et al. 2010). 
Seed treatments with Trichoderma viride or $T$. harzianum have yielded up to $70 \%$ disease reduction (Biswas et al. 2010). Over $70 \%$ disease reduction has been achieved from the use of selected Pseudomonas spp. isolates (Joshi et al. 2007; Ludwig et al. 2009). Direct foliar application of T. harzianum has also been reported to reduce the disease intensity and significantly improve grain yield, total grain carbohydrate and protein, in addition to a significant improvement in the total photosynthetic pigments in rice leaves (Abdel-Fattah et al. 2007).

The use of Trichoderma spp., well-known mycoparasites, can help by improving nutrients uptake and mobilization, enhancing nitrogen use efficiency, promoting root growth and plant biomass, and improving tolerance to various physiological stresses, including soil salinity and drought through the reduction of oxidative damage that stresses cause (Harman 2011; Shoresh et al. 2010). Use of these microbes could suppress disease through direct antagonism against the pathogen because imbalanced plant nutrition and drought stresses are predisposing factors for BS development. This effect would be combined with improved plant nutrient supply and delayed onset of water deficit in plant tissues (Bae et al. 2009) altering plant physiology to the disadvantage of the pathogen. Further, these microorganisms could contribute to the build-up of active plant immunity through the activation of the defence pathways, similar to the effects of $P$. fluorescens on rice, which induces resistance to sheath blight (Nandakumar et al. 2001).

Biocontrol agents are likely to interact with other disease management elements, especially host plant resistance, as well as plant growth related or abiotic stressrelated, genes: research leading to an understanding of such interactions at the molecular level could in itself provide insights on the physiology of environmental stresses, of disease and their interactions.

\section{Conclusions and perspectives}

This review addressed a series of facets of one complex disease of rice. Many of the questions listed in the introduction remain unanswered or addressed in a qualitative rather than in a quantitative manner. Central to explain the behaviour of the BS pathosystem and control are the linkages between the pathogen, the host and their environments with numerous factors involved.
This review also underscores the need for a better quantification of processes involved in the life cycle of the pathogen. This particularly concerns the measurement of the latency period, its variability and the effect of environmental factors. Measuring the infectious period would also enable a complete quantitative coverage of the monocycle in BS, with several applications, one of them being a full development of operational definitions for components of resistance.

Another area concerns the complex soil water/ nutrient - plant physiology — plant susceptibility interactions where a systems approach at different levels of biological integration addressing the host crop, its physiology, a pathogen, their biological and physical environments and their interactions is required. The factors involved are so numerous; the interactions so complex and often non-linear, that only a strong modelling effort could ensure progress. The work conducted by Carvalho et al. (2010) demonstrated that a whole-plant approach is necessary and could be very rewarding in both the fields of breeding and biocontrol.

Despite the progress recently achieved in the area of characterizing sources of resistance and their genetic bases, this area suffers of a lack of connection with the host-pathogen relationships and their translation in epidemics. Another area of priority concerns the development of methods to measure the disease response, within its cycle: only accurate, standardized, information on the variation of components of resistance will enable to guide breeding, as well as biocontrol research. Here again, simulation modelling could provide a useful operational framework.

Many farmers in South Asia, particularly India, are practising biological control of BS and other fungal diseases of rice. Seed treatment with biocontrol agents is becoming increasingly popular. Research into the mechanisms underpinning biocontrol agents interactions with host plant resistance and plant physiology and the contribution of biocontrol agents to nutrient uptake, better growth, tolerance to environmental stresses, could pave the way towards novel understandings of plant-pathogen interactions, as well as providing means to sustain the adoption of durable disease management practices by farmers.

This review highlights that brown spot remains a poorly defined rice crop health problem being a reflection of the large number of factors determining the course of epidemics and their outcomes. While a lack of understanding of the pathogen's life cycle and how it 
is influenced by environmental factors contributes to this poor definition, understanding the effects of global change and of shifts in socio-economic contexts, which determine crop management and inputs, make BS a marker of global and climate changes. Such interactions are not unique. Brown spot may thus be seen as a model system to characterize the behaviour of many complex pathosystems responding to unfolding climate and global changes.

Open Access This article is distributed under the terms of the Creative Commons Attribution License which permits any use, distribution, and reproduction in any medium, provided the original author(s) and the source are credited.

\section{References}

Abdel-Fattah, G. M., Shabana, Y. M., Ismail, A. E., \& Rashad, Y. M. (2007). Trichoderma harzianum: a biocontrol agent against Bipolaris oryzae. Mycopathologia, 164, 81-89.

Adair, C. R. (1941). Inheritance in rice of reaction to Helminthosporium oryzae and Cercospora oryzae. Technical Bulletin, United States Department of Agriculture No. 772.18 pp.

Akai, S., Shishiyama, J., \& Nishimura, R. (1965). Effect of spore density on the pathogenicity of Helminthosporium oryzae to rice leaves. Annals of Phytopathological Society of Japan, 30, 166-168.

Allaway, W. W. (1968). Agronomic controls over the environmental cycling of trace elements. Advances in Agronomy, 20, 235-274.

Allorent, D., \& Savary, S. (2005). Epidemiological characteristics of angular leaf spot of bean: a systems analysis. European Journal of Plant Pathology, 113, 329-341.

Allorent, D., Willocquet, L., Sartorato, A., \& Savary, S. (2005). Quantifying and modelling the mobilisation of inoculum from diseased leaves and infected defoliated tissues in epidemics of angular leaf spot of bean. European Journal of Plant Pathology, 113, 377-394.

Aluko, M. O. (1975). Crop losses caused by brown leaf spot disease of rice in Nigeria. Plant Disease Reporter, 59, 609-613.

Ba, V. V., \& Sangchote, S. (2006). Seedborne and transmission of Bipolaris oryzae, the causal pathogen of brown spot of rice. Kasetsart Journal, Natural Sciences, 40, 353-360.

Bae, H., Sicher, R. C., Kim, M. S., Kim, S., Strem, M. D., Melnick, R. L., et al. (2009). The beneficial endophyte Trichoderma hamatum isolate DIS $219 \mathrm{~b}$ promotes growth and delays the onset of the drought response in Theobroma cacao. Journal of Experimental Botany, 60, 3279-3295.

Balal, M. S., Omar, R. A., El-Khadem, M. M., \& Aidy, I. R. (1979). Inheritance of resistance to the brown spot disease of rice, Cochliobolus miyabeanus. Agricultural Research Review, 57, 119-133.

Bedi, K. S., \& Gill, H. S. (1960). Losses caused by the brown leaf spot disease in the Punjab. Indian Phytopathology, 13, 161-164.
Biswas, S. K., Ratan, V., Srivastava, S. S. L., \& Singh, R. (2008). Influence of seed treatment with biocides and foliar spray with fungicides for management of brown leaf spot and sheath blight of paddy. Indian Phytopathology, 61, 55-59.

Biswas, C., Srivastava, S. S. L., \& Biswas, S. K. (2010). Effect of biotic, abiotic and botanical inducers on crop growth and severity of brown spot in rice. Indian Phytopathology, 63, 187-191.

Bergamin Filho, A. B., Carneiro, S. M. T. P. G., Godoy, C. V., Amorim, L., Berger, R. D., \& Hau, B. (1997). Angular leaf spot of Phaseolus beans: relationships between disease, healthy leaf area and yield. Phytopathology, 87, 506-515.

Carvalho, M. P., Rodrigues, F. A., Silveira, P. R., Andrade, C. C. L., Baroni, J. C. P., Paye, H. S., et al. (2010). Rice resistance to brown spot mediated by nitrogen and potassium. Journal of Phytopathology, 158, 160-166.

Chakrabarti, N. K., Chaudhuri, S., Singh, U.S., Mukhopadhyay, A. N., Kumar, J., \& Chaube, H. S. (1992). Brown spot of rice. Plant diseases of international importance. Volume I. Diseases of cereals and pulses. pp. 116-129.

Chakrabarti, N. K. (2001). Epidemiology and disease management of brown spot of rice in India. In: Major Fungal Disease of Rice: Recent Advances. Kluwer Academic Publishers. pp. 293-306.

Chattopadhyay, S. B., \& Chakrabarti, N. K. (1965). Effect of agronomic practices on susceptibility of rice plants to infection of Helminthosporium oryzae. Rice Newsletter, 13, 39-44.

Chattopadhyay, S. B., \& Dickson, J. G. (1960). Relation of nitrogen to disease development in rice seedlings infected with Helminthosporium oryzae. Phytopathology, 50, 434-438.

Damicone, J., Moore, B., Fox, J., \& Sciumbato, G. (2001). Rice diseases in Mississippi: A guide to identification. Mississippi State University Extension Service.

Dasgupta, M. K., \& Chattopadhyay, S. B. (1977). Effect of environmental factors on the development of brown spot of rice caused by Helminthosporium oryzae. Journal of the Society of Experimental Agriculturists, 2, 24-27.

Dallagnol, L. J., Rodrigues, F. A., Damatta, F. M., Mielli, M. V. B., $\&$ Pereira, S. C. (2010). Deficiency in silicon uptake affects cytological, physiological and biochemical events in the riceBipolaris oryzae interaction. Phytopathology, 101, 92-104.

Datnoff, L. E., Raid, R. N., Snyder, G. H., \& Jones, D. B. (1991). Effect of calcium silicate on blast and brown spot intensities of rice. Plant Disease, 75, 729-732.

Datnoff, L. E., Deren, C. W., \& Snyder, G. H. (1997). Silicon fertilization for disease management of rice in Florida. Crop Protection, 16, 525-531.

Duveiller, E., \& Sharma, R. C. (2009). Genetic improvement and crop management strategies to minimize yield losses in warm non-traditional wheat growing areas due to spot blotch pathogen Cochliobolus sativus. Journal of Phytopathology, 157, 521-534.

Ellis, M. B., \& Holliday, P. (1971). Cochliobolus miyabeanus. Descriptions of fungi and bacteria. UK: CAB International. $302 \mathrm{pp}$.

Fomba, S. N., \& Singh, N. (1990). Crop losses caused by brown spot disease in mangrove swamps of North Sierra Leone. Tropical Pest Management, 36, 387-393.

Gangopadhyay, S., \& Chakrabarti, N. K. (1987). Epidemiology of brown spot disease of rice. In: Advances in Rice Pathology. 
Tamil Nadu Agricultural University, Coimbatore, Tamil Nadu, India. 484 pp.

Gardner, F. P., Pearce, R. B., \& Mitchell, R. L. (1985). Physiology of crop plants. Ames: The Iowa State University Press. 327 p.

Goel, R. K., Bala, R., \& Singh, K. (2006). Genetic characterization of resistance to brown leaf spot caused by Drechslera oryzae in some wild rice (Oryza sativa) lines. Indian Journal of Agricultural Sciences, 76, 705-707.

Harman, G. E. (2011). Trichoderma - not just for biocontrol anymore. Phytoparasitica, 39(2), 103-108.

Hegde, Y., Angadi, V. V., \& Mohankumar, H. D. (1999). Effect of irrigation on the incidence of brown spot of rice. Karnataka Journal of Agricultural Sciences, 12, 200-201.

Hemmi, T., \& Suzuki, H. (1931). On the relation of soil moisture to the development of Helminthosporium disease of rice seedlings. Forschungen aus dem Gebiet der Pflanzenkrankheiten, 1, 90-98.

Hossain, M., Khalequzzaman, K. M., Mollah, M. R. A., Hussain, M. A., \& Rahim, M. A. (2004). Reaction of breeding lines/ cultivars of rice against brown spot and blast under field condition. Asian Journal of Plant Sciences, 3, 614-617.

Igawa, T., Tokal, T., Kudo, T., Yamagushi, I., \& Kimura, M. (2005). A wheat xylanase inhibitor gene, Xip-I, but not Taxi-I, is significantly induced by biotic and abiotic signals that trigger plant defense. Bioscience, Biotechnology, and Biochemistry, 69, 1058-1063.

Imura, J. (1940). On the influence of sunlight upon the incubation period of the Helminthosporium disease of the rice plant. Annals of the Phytopathological Society of Japan, 10, 16-26.

Joshi, N., Brar, K. S., Pannu, P. P. S., \& Singh, P. (2007). Field efficacy of fungal and bacterial antagonists against brown spot of rice. Journal of Biological Control, 21, 159-162.

Katara, J. L., Sonah, H., Deshmukh, R. K., Chaurasia, R., \& Kotasthane, A. S. (2010). Molecular analysis of QTLs associated with resistance to brown spot in rice (Oryza sativa L.). Indian Journal of Genetics and Plant Breeding, 70, 17-21.

Kulkarni, S., Ramakrishnan, K., \& Hegde, R. K. (1979). Dose response in Drechslera oryzae (Breda de Haan) - a causal agent of brown leaf spot of rice. Current Research, 8, 194.

Klomp, A. O. (1977). Early senescence of rice and Deschlera oryzae in Wageningen polder. Wageningen: Surinam Agricultural Research Report. No 859.

Levy, Y., \& Cohen, Y. (1980). Sporulation of Helminthosporium turcicum on sweet corn: Effects of temperature and dew period. Canadian Journal of Plant Pathology, 2, 65-69.

Ludwig, J., Moura, A. B., dos Santos, A. S., \& Ribeiro, A. S. (2009). Seed microbiolization for the control of rice brown spot and leaf scald. Tropical Plant Pathology, 34, 322-328.

Luo, W. H. (1996). Simulation and measurement of leaf wetness formation in paddy rice crops. Wageningen: PhD Thesis, Wageningen Agricultural University.

Ma, J. F., Tamai, K., Yamaji, N., Mitani, N., Konishi, S., Katsuhara, M., Ishiguro, M., Murata, Y. \& Yano, M. (2006). A silicon transporter in rice. Nature, 440, 688-91.

Ma, J. F., Yamaji, N., Mitani, N., Tamai, K., Konishi, S., Fujiwara, T., Katsuhara, M. \& Yano, M. (2007). An efflux transporter of silicon in rice. Nature, 448, 209-12.

Minnatullah, M. D., \& Sattar, A. (2002). Brown spot development in Boro rice as influenced by weather condition. Journal of Applied Biology, 12, 71-73.
Misawa, T. (1955). Studies on the Helminthosporium leaf spot of rice plant. Jubilee Publication in Commemoration of the 60th Birthdays of Professors Y. Tochinai and T. Fukushi, 65-73.

Nandakumar, R., Babu, S., Viswanathan, R., Raguchander, T., \& Samiyappan, R. (2001). Induction of systemic resistance in rice against sheath blight disease by Pseudomonas fluorescens. Soil Biology and Biochemistry, 33, 603-612.

Nagai, I., \& Hara, S. (1930). On the inheritance of variegation disease in a strain of rice plant. Japanese Journal of Genetics, $5,140-144$.

Nisikado, Y. (1923). Effect of temperature on the growth of Helminthosporium oryzae $\mathrm{Br}$. De Haan. Annals of the Phytopathological Society of Japan, 1, 20-30.

Nyvall, R. F., Percich, J. A., Porter, R. A., \& Brantner, J. R. (1995). Comparison of fungal brown spot severity to incidence of seedborne Bipolaris oryzae and B. sorokoniana and infected floral sites on cultivated wild rice. Plant Disease, 79, 249-250.

Ou, S. H. (1985). Rice disease (2nd ed.). Kew: Commonwealth Mycological Institute. $380 \mathrm{pp}$.

Padmanabhan, S. Y., \& Ganguly, D. (1954). Relation between the age of the rice plant and its susceptibility to helminthosporium and blast disease. Indian Academy of Science, 29, 44-50.

Padmanabhan, S. Y., Abichandrani, T. G., Chakrabarti, N. K., \& Patnaik, S. (1962). Studies on Helminthosporium disease of rice. VI. Nutritional factors and disease expression- 2. Effect of potassium. Proceedings of the Indian Science Congress, Part III. p. 480.

Padmanabhan, S. Y. (1973). The great Bengal Famine. Annual Review of Phytopathology, 11, 11-26.

Pannu, P. P. S., Chahal, S. S., Kaur, M., \& Sidhu, S. S. (2005). Influence of weather variable on the development of brown leaf spot caused by Helminthosporium oryzae in rice. Indian Phytopathology, 58, 489-492.

Phelps, R. H., \& Shand, C. R. (1995). Brown leaf spot disease and fertilizer interaction in irrigated rice growing on different soil types. Nutrient Cycling in Agroecosystems, 42, $117-121$.

Percich, J. A., Nyvall, R. F., Malvick, D. K., \& Kohls, C. L. (1997). Interaction of temperature and moisture on infection of wild rice by Bipolaris oryzae in the growth chamber. Plant Disease, 81, 1193-1195.

Rabbinge, R., \& Vereyken, P. H. (1980). The effect of diseases or pests upon the host. Zeitschrift für Pflanzenkrankheiten und Pflanzenschutz, 87, 409-422.

Rabbinge, R., \& Rijsdijk, F. H. (1981). Disease and crop physiology: a modeler's point of view. In: Effects of Disease on the Physiology of the Growing Plant. Ayres, P. G., Ed. Cambridge Univ. Press, Cambridge (258p.).

Rabbinge, R. (1982). Pests, diseases and crop production. In: Simulation of Plant Growth and Crop Production. Penning de Vries, F. W. T. \& Van Laar, H. H., Eds. Pudoc, Wageningen, pp. 253-265.

Reddy, A. P. K., Katyal, J. C., Rouse, D. I., \& MacKenzie, D. R. (1979). Relationship between nitrogen fertilization, bacterial leaf blight severity and yield of rice. Phytopathology, 69, 970-973.

Reddy, C. S., Laha, G. S., Prasad, M. S., Krishnaveni, D., Castilla, N. P., Nelson, A., et al. (2010). Characterizing multiple linkages between individual diseases, crop health syndromes, germplasm deployment and rice production situations in India. Field Crops Research, 120, 241-253. 
Sarkar, A. K., \& Sen Gupta, P. K. (1977). Effect of temperature and humidity on disease development and sporulation of Helminthosporium oryzae on rice. Indian Phytopathology, 30, 258-259.

Satija, A., Chahal, S. S., \& Pannu, P. P. S. (2005). Evaluation of rice genotypes against brown leaf spot disease. Plant Disease Research (Ludhiana), 20, 163-164.

Sato, H., Ando, I., Hirabayashi, H., Takeuchi, Y., Arase, S., Kihara, J., et al. (2008). QTL analysis of brown spot resistance in rice (Oryza sativa L.). Breeding Science, 58, 93-96.

Savary, S., Willocquet, L., \& Teng, P. S. (1997). Modelling sheath blight epidemics on rice tillers. Agricultural Systems, 55, 359-384.

Savary, S., Willocquet, L., Elazegui, F. A., Teng, P. S., Du, P. V., Zhu, D., et al. (2000a). Rice pest constraints in tropical Asia: characterization of injury profiles in relation to production situations. Plant Disease, 84, 341-356.

Savary, S., Willocquet, L., Elazegui, F. A., Castilla, N., \& Teng, P. S. (2000b). Rice pest constraints in tropical Asia: quantification of yield losses due to rice pests in a range of production situations. Plant Disease, 84, 357-369.

Savary, S., Castilla, N. P., Elazegui, F. A., \& Teng, P. S. (2005). Multiple effects of two drivers of agricultural change, labour shortage and water scarcity, on rice pest profiles in tropical Asia. Field Crops Research, 91, 263-271.

Savary, S., Teng, P. S., Willocquet, L., \& Nutter, F. W., Jr. (2006). Quantification and modeling of crop losses: a review of purposes. Annual Review of Phytopathology, 44, 89-112.

Savary, S., Nelson, A., Sparks, A. H., Willocquet, L., Duveiller, E., Mahuku, G., et al. (2011). International agricultural research tackling the effects of global and climate changes on plant diseases in the developing world. Plant Disease, Plant Disease, 48, 1-40.

Savary, S., Nelson, A., Willocquet, L., Pangga, I., \& Aunario, J. (2012). Modeling and mapping potential epidemics of rice diseases globally. Crop Protection, 34, 6-17.

Schoeneweiss, D. F. (1975). Predisposition, stress and plant disease. Annual Review of Phytopathology, 13, 193-211.

Segarra, J., Jeger, M. J., \& Van den Bosch, F. (2001). Epidemic dynamics and patterns of plant diseases. Phytopathology, 91, 1001-1010.

Singh, R. K., Singh, C. V., \& Shukla, V. D. (2005). Phosphorus nutrition reduces brown spot incidence in rainfed upland rice. International Rice Research Notes, 30(2), 31-32.

Sharma, S. K., \& Maheshwari, S. K. (1982). Efficacy of fungicides for the control of brown spot. International Rice Research Notes, 7, 5.

Sherf, A. F., Page, R. M., Tullis, E. C., \& Morgan, T. L. (1947). Studies on factors affecting the infectivity of Helminthosporium oryzae. Phytopathology, 37, 281-290.

Shoresh, M., Harman, G. E., \& Mastouri, F. (2010). Induced systemic resistance and plant responses to fungal biocontrol agents. Annual Review of Phytopathology, 48, 21-43.

Shukla, V. D., Chauhan, J. S., Variar, M., Maiti, D., Chauhan, V. S., \& Tomar, J. B. (1995). Reaction of traditional rainfed rice accessions to brown spot, blast and sheath rot diseases. Indian Phytopathology, 48, 433-435.

Spradley, P., Shipp, M., Grodner, M., \& Collum, E. (2003). Pest Management Strategic Plan for Midsouth Rice (Arkansas, Louisiana, Mississippi). 58 pp.

Su, M.T. (1938). Report of the Mycologist, Burma, Mandalay, for the year ending 31st March, 1938. Report on the Operations Department of Agriculture, Burma, 1937-38, 45-54.

Thal, W. M., \& Campbell, C. L. (1988). Analysis of progress of alfalfa leaf spot epidemics. Phytopathology, 78, 389-395.

Timmusk, S., \& Wagner, E. G. H. (1999). The plant-growthpromoting rhizobacterium Paenibacillus polymyxa induces changes in Arabidopsis thaliana gene expression: A possible connection between biotic and abiotic stress responses. Molecular Plant-Microbe Interactions, 12, 951-959.

Van der Plank, J. E. (1963). Plant diseases. Epidemics and control. New York: Academic.

Vidhyasekharan, P., Ramadoss, N., \& Srinivasalu, N. (1973). Quantitative and qualitative losses in paddy due to Helminthosporiose epidemic. Indian Phytopathology, 26, 479-484.

Wang, T. S. L., Hsu, L. S., \& Lin, C. H. (1980). Improvement of soil fertility for reducing brown spot incidence in paddy fields of Eastern Taiwan. Journal of Agricultural Research of China, 29, 35-46.

Weil, R. R., \& Holah, S. S. (1989). Effect of submergence on availability of certain plant nutrients in three Ultisol catenas. Plant and Soil, 114, 147-157.

Willocquet, L., Fernandez, L., \& Savary, S. (2000). Effect of various crop establishment methods practised by Asian farmers on epidemics of rice sheath blight caused by Rhizoctonia solani. Plant Pathology, 49, 346-354.

Willocquet, L., Elazegui, F. A., Castilla, N. P., Fernandez, L., Fischer, K. S., Peng, S., et al. (2004). Research priorities for rice disease and pest management in tropical Asia: a simulation analysis of yield losses and management efficiencies. Phytopathology, 94, 672-682.

Yamaji, N., Mitatni, N., \& JianFeng, M. (2008). A transporter regulating silicon distribution in rice shoots. The Plant Cell, 1381-1389.

Yoshida, S. (1981). Fundamental of rice crop science. Los Baños: IRRI.

Zadoks, J. C. (1971). Systems analysis and the dynamics of epidemics. Phytopathology, 61, 600-610.

Zadoks, J. C. (1974). The role of epidemiology in modern Phytopathology. Phytopathology, 64, 918-929.

Zadoks, J. C. (2008). On the political economy of plant disease epidemics-capita selecta in historical epidemiology. Wageningen: Wageningen Academic. 249p.

Zanão Júnior, L. A., Rodrigues, F. Á., Fontes, R. L. F., Korndörfer, G. H., \& Neves, J. C. L. (2009). Rice resistance to brown spot mediated by silicon and its interaction with manganese. Journal of Phytopathology, 157, 73-78. 